\title{
Contribuições da psicanálise à atuação na clínica cardiológica
}

\author{
Dorivaldo Pantoja Borges Junior* \\ Gabrielle de Kassia Carrera de Oliveira* \\ Ana Carolina Peck Vasconcelos**
}

\begin{abstract}
Resumo
O presente ensaio tem como objetivo refletir sobre as contribuições psicanalíticas à atuação do psicólogo/psicanalista na clínica cardiológica a partir de uma breve articulação e discussão teóricas. Lançou-se mão de compreensões tais quais a inserção do analista no hospital, o corpo adoecido para a psicanálise e os principais aspectos subjetivos presentes na clínica cardiológica. Concluiu-se que o cerne das contribuições psicanalíticas à problemática é o oferecimento de possibilidade de acesso ao simbólico, diante de conteúdos difíceis de ser elaborados, que emergem a partir do processo de adoecimento.

Palavras-chave: Clínica cardiológica; Psicanálise; Psicologia hospitalar.
\end{abstract}

\section{Contributions of psychoanalysis to performance at the cardiology clinic}

\begin{abstract}
This essay aims to reflect on the psychoanalytic contributions to the role of the psychologist/psychoanalyst in the cardiology clinic from a brief articulation and theoretical discussion. Understandings such as the insertion of the analyst in the hospital, the sick body for psychoanalysis and the main subjective aspects present in the cardiology clinic were used. It was concluded that the core of psychoanalytic contributions to the problem is the possibility of providing access to the symbolic, in view of content that is difficult to elaborate, which emerge from the illness process. Keywords: Cardiologiy clinic ; Psychoanalysis ; Hospital psychologic.
\end{abstract}

* Graduando em Psicologia pela Universidade da Amazônia - UNAMA

** Graduada em Psicologia pela Universidade da Amazônia (UNAMA) e Mestre em Psicologia pela Universidade Federal do Pará - PPGP/UFPA. Psicanalista com formação pelo Círculo Psicanalítico do Pará - CPPA e Docente na Universidade da Amazônia (UNAMA) 


\section{Introdução}

As preocupações a respeito do sofrimento humano inauguraram discussões que atravessam diversas áreas do saber como: filosofia, sociologia, psicanálise, entre outras. De maneira geral, pode-se elucidar o sofrimento a partir de sua ideia primeira: o Pathos, o que padece o sujeito, que se manifesta no corpo e o deixa passivo, denotando a necessidade de outros externos (Berlinck, 2000).

Nesse sentido, o presente ensaio bibliográfico tem como objetivo traçar possíveis compreensões sobre as contribuições psicanalíticas à atuação na clínica cardiológica a partir da articulação de proposições teóricas que proporcionem o desenvolvimento do debate sobre a temática da Psicologia da Saúde e, mais especificamente sobre o saber psicanalítico inserido em cenários externos ao setting clínico tradicional.

O cenário que contempla as problematizações aqui dispostas é a clínica cardiológica presente no hospital que, por si, comporta inúmeros desafios no tocante as especificidades dessa clínica (Lamosa, 1990). Enquanto área médica, a Cardiologia é apresentada inicialmente com a aplicação no contexto de trabalho a partir de um prisma médico-social e obteve, com o tempo, crescimento e consolidação (Souza, 2017). Entretanto, no que diz respeito ao subjetivo, a área ganha uma maior amplitude.

Por conta de seu caráter mais paliativo em detrimento do curativo, a Cardiologia se mostra como um grande desafio ao profissional que se dispõe a cuidar dos construtos subjetivos envolvidos, já que uma patologia cardiovascular obriga o sujeito a modificar todo o seu estilo de vida (Oliveira \& Oliveira, 2010). Dessa forma, lançando o paciente a um luto (pela perda da condição de ser saudável) e à diversas fantasias, desde a possibilidade de morte, falha de procedimentos médicos (cirurgias/) e alterações do esquema corporal do sujeito.

Neste contexto, compreende-se que diferente da Psicologia, a Psicanálise tem seu foco nas manifestações do inconsciente, o que atribui a sua epistemologia outra característica, a de que não são os processos de domínio consciente que detém a verdade sobre um sujeito, mas estes são da ordem do desejo e das pulsões (Freud, 1930/2018).

$\mathrm{Na}$ tentativa de buscar respostas às indagações, utilizou-se os apontamentos psicanalíticos para compreender as manifestações subjetivas presentes na clínica cardiológica. Como metodologia, fez-se uso de um ensaio bibliográfico, que é estruturado como uma tentativa de discussão e reflexão de ideias a partir de uma questão norteadora. Embora tenha uma certa sistematização, a produção de um ensaio acadêmico é mais livre quanto sua composição bibliográfica e argumentativa (Lira, 2015). Sendo assim, a argumentação construída baseou-se nas possíveis contribuições psicanalíticas à atuação frente aos aspectos subjetivos emergentes na clínica cardiológica.

No tocante a este contexto, o percurso teórico deste ensaio fora estruturado a partir dos seguintes apontamentos: primeiramente apresentou-se a inserção do psicanalista no hospital, seus desafios e alcances para, em seguida discorrer brevemente, a respeito do lugar do corpo adoecido para a psicanálise. Em seguida, abordaram-se os principais aspectos subjetivos presente na clínica cardiológica.

Frente a isso, identificou-se que as contribuições do psicanalista aos sujeitos padecidos do "coração" é o oferecimento do simbólico ao processo de elaboração do adoecimento, questões que são abordadas como considerações finais.

\section{O que faz o analista no hospital?}

O hospital é lugar em que se encontram realidades internas e externas urgentes e demasiado hostis para as quais se deve "olhar o corpo, o sujeito, a equipe, deixar-se invadir pelas percepções, vê-las para toma-las à escuta" (Gomes e Próchno, 2015, p. 789), de forma que o analista, segundo Fernandes (2005), por meio de escuta, possibilite a instauração de um discurso, não psicológico, mas psicanalítico, no qual os pacientes possam se constituir enquanto sujeitos desejantes, mesmo diante de seu processo de adoecimento

A escuta oferecida pelo analista não se configura como uma escuta familiar ao vocabulário popular, trata-se de uma escuta com um fim proposto. O que a escuta psicanalítica busca contemplar é o sujeito do inconsciente, diferindo então de qualquer intervenção profissional no âmbito da saúde que não se proponha a tratar desse sujeito (Moretto, 2002). Fala-se em uma escuta especializada, pois "nenhum outro membro da equipe tem treinamento para trabalhar no campo das palavras, que é exatamente onde o psicólogo é especialista" (Simonetti, 2004, p. 23).

Nessa perspectiva, pode-se buscar nos escritos de Moretto (2002) a questão do espaço do analista dentro da instituição hospitalar e da equipe multiprofissional. Um suposto empecilho na atuação do analista dentro do hospital seria a questão do setting analítico, pois este é tido como um conjunto de regras que cerceiam a atuação analítica e que, consequentemente, possibilitariam o "fazer psicanálise". Mas ao levar em consideração o que diz Freud (1913/2017) no artigo "Sobre o início do tra- 
tamento", seria mais bem posto apresentar esse conjunto de regras como recomendações, sem necessariamente atribuir-lhes uma obrigatoriedade, haja vista que:

A diversidade extraordinária das constelações psíquicas em questão, a plasticidade de todos os processos anímicos e a riqueza de fatores determinantes também se opõem a uma mecanização da técnica e permitem que um procedimento usualmente justificado por vezes se torne sem efeito [...] (FREUD, 1913 [2017], p. 121-123).

Sendo assim, utilizando-se do questionamento de Moretto (2002, p. 58):

Se Freud fazia suas intervenções analíticas andando a pé nos bosques de Viena, nos hotéis quando de suas viagens, se Lacan atendia nos corredores do hospital de Sainte-Anne, de onde surgiram essas regras que passaram a constituir o setting psicanalítico?

Não seria a associação livre a única regra da psicanálise? Nesse sentido, conforme Herrmann (2002, p.290) "nosso método é eficaz e dadivoso. Não se contenta em ser exercido no contexto da psicanálise de consultório, mas cria a atmosfera analítica onde quer que o empregue". Portanto, se existe uma demanda pela atuação do analista dentro da instituição de saúde, logo, pode-se afirmar que há ali naquele espaço um lugar reservado a este profissional.

Todavia, o que comumente ocorre é uma queixa pela falta de espaço, pois segundo Moretto (2002), o analista sente que está ali na função de ajudante do médico, uma vez que, para o profissional da medicina a ajuda dos profissionais "psis" (psicólogos e psicanalistas) lhe é útil quando algo, que lhe é estranho, conturba o andamento de seu trabalho; não havendo tais imprevistos, a ajuda do analista é dispensada e este cai no esquecimento. Mas é válido ressaltar que o psicanalista não ocupa o lugar de ajudante do médico, pois seu lugar é no psiquismo do paciente (Moretto, 2002).

De tal forma, se a medicina privilegia o corpo biológico do sujeito hospitalizado, a escuta analítica tratará do corpo simbólico do paciente. E é justamente nas palavras que habita esse corpo simbólico; o sujeito fala através de seu sintoma fazendo com que o objetivo do analista seja escutar o que há para ser dito, uma vez que:

Para a psicologia todo sintoma além de doer e fazer sofrer carrega em si uma dimensão de mensagem, comporta informações sobre a subjetividade do paciente, havendo mesmo a noção de que o sujeito fala por meio de seus sintomas, ou é falado por eles. E a psicologia escuta (SIMONETTI, 2004, p. 22).

No hospital, a demanda é a de acalmar, acabar com a angústia que aflige o paciente. Em seguida, analisa essa demanda como um pedido para "tapar um buraco", apresentando fórmulas que visam evitar a angústia. E essa angústia, na visão psicanalítica, é definida por uma não simbolização, que Moretto (2002) chama de "buraco do real", dessa forma, a oferta de escuta possibilita que o paciente dê significado a pelo menos uma parte desse real, e, consequentemente, apaziguando a angústia.

É nesse exercício de fala e escuta - o exercício da conversa como é comumente reconhecido o trabalho do psicólogo - que o paciente terá a oportunidade de atribuir um significado ao seu sintoma. Nessa conversa assimétrica (Simonetti, 2004), o silêncio do psicólogo exercerá um peso, necessário, sobre o paciente, silêncio que provoca uma suposição de saber (Moretto, 2002). O analista é colocado nessa posição de suposto saber pelo paciente, o que permite o vínculo transferencial, possibilitando o início do processo analítico. Inclui a instituição hospitalar, pois o analista exerce seu trabalho a partir de um lugar psíquico que não está atrelado necessariamente ao espaço físico.

O hospital é um ambiente no qual os familiares/ acompanhantes, na maioria das vezes, se propõem a dar conselhos ao paciente a respeito do que este deve fazer. Ou de como ele deve se portar diante do próprio sofrimento, ignorando em muitos momentos o que ele tem a dizer, negando sua subjetividade. Certamente não é a melhor postura frente a condição daquele que ali está hospitalizado. Entretanto, muitas vezes é a única saída que o familiar/acompanhante encontra diante da situação.

Com isso, observa-se que o foco do analista não se encontra somente na pessoa do paciente. Mas, principalmente, nos aspectos psicológicos que giram em torno do adoecimento, que estão encarnados nas pessoas da família e nos profissionais que compõem a equipe multiprofissional (Simonetti, 2004). Estes últimos, quando se deparam com a fragilidade do doente, tendem a apresentar sinais de desamparo diante da impotência dos cuidados e da morte. Dessa forma, "cabe ao analista sustentar esse espaço de invenção para o sujeito, onde ele será convidado a (re)inventar, através da palavra, um modo próprio de se haver com o insuportável, reconstruir um sentido a partir de algo que aponta para um enigma" (Batista \& Rocha, 2013, p. 13). 
Posto isso, cabe pensar a desterritorialização que o sujeito sofre em relação ao seu próprio corpo em meio ao contexto de internação hospitalar, uma vez que, dentro dessa realidade, estará entregue aos cuidados de outras pessoas. Além de ser retirado de sua rotina e se alojar em um espaço que lhe é estranho, que não lhe pertence e no qual é confrontado com sua condição de sujeito faltante.

\section{Considerações psicanalíticas acerca do corpo hospitalizado}

Tendo em vista a importância do olhar sobre o corpo hospitalizado, Gomes (2008) ressalta que "a reflexão histórica sobre o corpo se apresenta como tema central na consideração da subjetividade do sujeito ante o adoecimento e a hospitalização nos dias atuais" (p. 23). O corpo se entrelaça à cultura, a história e a sociedade, portanto, se vê carregado de significados correspondentes ao período histórico e ao meio cultural no qual se encontra inserido. Nessa época pós-moderna, lança-se ao sujeito "o desafio de como transcender o inevitável - a morte, o envelhecimento, a doença" (Gomes, 2008, p. 23).

Gomes \& Próchno (2015) ressaltam que:

A busca é por um corpo que tange o mítico, o divino e o imortal, um corpo característico do jogo de transformações que essa realidade contemporânea apresenta, marcada acentuadamente pela troca de lugares, troca de corpos, troca de identidades, de tribos, de guetos e pela mobilidade pungente de representações dos tempos pós-modernos. Frente à hospitalização e ao encontro com a doença essa idealização mítica sofre grande abalo (Gomes \& Próchno, 2015, p.782).

Freud (1930/2018), no artigo "O mal-estar na civilização", disserta que o sofrimento humano advém de três direções: aquele sofrimento que se origina em fontes externas, correspondente às catástrofes naturais, situações que não se podem prever; o sofrimento advindo das relações estabelecidas com o outro, seu semelhante; e por último, o sofrimento que parte do próprio corpo do sujeito. Essas três fontes se constituem então como fontes de desamparo humano.

A compreensão de desamparo para a psicanálise remete ao estado inicial do sujeito - período de dependência materna para a sobrevivência, que em situações extremas podem ressurgir. Dessa forma, "as situações de desamparo nos remetem a experiências nas quais nosso aparelho psíquico é invadido por uma angústia tal que não podemos dar vazão a mesma, na medida em que não há representações disponíveis para sua simbolização" (Bento, 2008, p. 103).

Assim sendo, dar-se-á uma atenção maior sobre a terceira fonte de sofrimento humano - a qual diz respeito ao desamparo advindo do padecimento orgânico do corpo do sujeito (Freud, 1930/2018). Tem-se que o corpo humano da contemporaneidade exerce papel essencial no imaginário social e individual, uma vez que pressiona o sujeito a negar sua própria limitação na tentativa de olvidar sua existência marcada pela finitude e os episódios de doença (Gomes \& Próchno, 2015).

Em vista disso, têm-se que corpo e psiquismo são indissociáveis e a fronteira existente entre essas duas partes é volátil. Sabe-se que nem toda enfermidade que acomete o corpo se origina no plano psíquico, portanto, é nessa conjuntura que o corpo, quando se vê frente a frente à limitação imposta por sua própria condição, deixa o indivíduo em um estado de desamparo e mal-estar (Bento, 2008; Gomes \& Próchno, 2015). Dessa forma:

O corpo doente, mostra-se desamparado frente à doença hospitalizada, frente à rapidez nas mudanças de exigências a ele nesta situação específica, frente às técnicas de manuseio e cuidados com o mesmo. Frente às exigências de ser para além de um corpo-saúde - um corpo-perfeito, escultural e um corpo-beleza -, temos um corpo-desamparo, emaranhado na sensação de vazio subjetivo, de desvitalização e de fragmentação. Essa realidade de corpo fragmentado, esvaziado e adoecido é uma realidade negada pela civilização contemporânea, que prima pelo ideal de um corpo belo, sadio e perfeito o tempo todo (Gomes \& Próchno, 2015, p. 784).

No ambiente hospitalar vê-se personificada a crença de que a instituição exerce poder sobre eventos como a vida, a doença e a morte. O paciente idealiza o local como detentor do saber e de cura (Imanishi \& Silva, 2016; Gomes \& Próchno, 2015). Logo, o hospital, enquanto instituição, está imerso nas questões pulsionais, de vida e morte, de fragmentação e reconstrução, dando, desse modo, subsídios para a formação de um espaço favorável ao desnudamento do desamparo humano (Gomes \& Próchno, 2015).

Para além das fantasias de saber e de cura que se criam em torno do hospital, tem-se nessa instituição um processo de destituição do sujeito (Ismael, 2010). A subjetividade do paciente passa despercebida, suscitando no fenômeno da despersonalização, e como contribuintes desse processo estão a institucionalização do sujeito, uma 
vez que, este vê-se obrigado a se submeter às regras do local; a perda de autonomia, tendo em vista a vulnerabilidade e suscetibilidade em relação ao outro, o profissional da saúde, devido aos procedimentos invasivos; e o tratamento não humanizado da equipe de saúde que, muitas vezes, trata a doença e não o humano adoecido Ismael (2010) apud Imanishi \& Silva (2016).

Deste modo, Gomes \& Próchno (2015, p. 787) contribuem com a discussão ao afirmarem que o adoecimento é uma ruptura que destitui o sujeito de sua subjetividade e o lança ao estado homogeneizador característico das instituições. Eles disseram que o sujeito:

[..] "É destituído primeiro pela doença do controle do seu corpo. Num segundo momento, a hospitalização o destitui da sua rotina, do domić́lio, dos hábitos, da privacidade. A sensação da finitude o destitui do campo das certezas e lança-o numa condição desterritorializante, que produz cisão e sofrimento."

O sujeito, quando se encontra adoecido e hospitalizado, lida com uma desestabilização emocional. No hospital a escuta contempla essa falta que desterritorializa e se revela em demandas que exibem um sujeito que sofre em sua tentativa de preservar sua ilusão de completude. Ao contrário da ideia de completude, o sujeito humano é marcado pela incompletude e a doença revela essa condição ao expô-la ao próprio sujeito e ao outro, a hospitalização escancara a falta que constitui o ser humano (Gomes \& Próchno, 2015; Moura, 2003).

$\mathrm{Na}$ clínica cardiológica, em específico, a marca da incompletude se revela pela falha do órgão que simboliza a vida. O coração adoecido recebe, através das crenças populares, maior destaque sobre as demais doenças, pois sendo ele, no imaginário popular, a representação da vida, qualquer situação de doença que lhe ocorra faz com que o sujeito encare não somente a consciência de sua finitude, como também outros aspectos subjetivos.

Aspectos psicológicos na clínica cardiológica

No que se refere ao processo de adoecimento, toda doença carrega em si uma carga subjetiva, dando assim a possibilidade de o sujeito hospitalizado usufruir dos serviços da psicologia hospitalar. Nessa conjuntura observa-se, que os sujeitos são dotados da capacidade de conferir sentido àquilo que vivenciam, inclusive ao processo de adoecimento (Simonetti, 2004). É, também, digno de nota o conhecimento de:
"O aspecto psicológico não ocorre isoladamente, mas se dá em uma determinada cultura, e cada cultura tem seus determinantes sobre a doença, tais como usos e costumes, mitos, folclores, condições econômicas, representações artísticas, etc. (Simonetti, 2004, p. 26).”

Do conjunto de sentidos que cria em volta do adoecimento, tem-se o campo dos aspectos psicológicos. No que diz respeito aos hospitais especializados no atendimento ao paciente com doenças cardiológicas é constante a presença de aspectos psicológicos implicados no processo de doença. (Padilha \& Kristensen, 2006).

Pois, quando se tratam das patologias que acometem o coração, deve-se levar em consideração a carga simbólica que o órgão carrega em si; o coração é um órgão que ganha conotações e implicações afetivas que ultrapassam os limites da anatomia (Aguiar, Cavalcante, Ramos \& Holanda, 2018; Oliveira, 2008). Ao coração é atribuído, socialmente, a qualidade de órgão propulsor da vida e, nessas circunstâncias, o adoecimento pela via cardíaca assume status de maior gravidade quando comparado as demais doenças que se infligem sobre o corpo humano.

Deve-se atentar também ao fato de que os sintomas da doença se coligam às questões de ordem emocional, haja vista as representações simbólicas do coração como fonte de vida e sede das emoções (Bonomo \& Araújo, 2009; Padilha \& Kristensen, 2006). D D s s a forma, as simbolizações que envolvem esse órgão levam à percepção de seu adoecimento como "uma ameaça à integridade e à própria vida, gerando ansiedade e angústia" (Ragozini, Almeida, Pereira \& Barbosa, 2010, p. 116). E partindo da compreensão de que tais crenças interferem no âmbito emocional do paciente cardiopata, tem-se então o campo dos aspectos psicológicos que compõem a clínica cardiológica

O homem enquanto sujeito de intenções, ao se encontrar enfermo, converte-se em sujeito de atenção sujeito que demanda atenção, demanda cuidados - e, por conseguinte, sua internação hospitalar se constitui mais um peso sobre o impacto psicossocial dessa condição de vida (Botega, 2017).

Padilha \& Kristensen (2006) afirmam que o processo de hospitalização desencadeia sentimentos de medo e ansiedade perante os procedimentos que têm um caráter invasivo, desconhecido, além do distanciamento social que acaba ocasionando e da situação de adoecimento em si. Nesse sentido, Strain (1978) denota oito categorias de estresse psicológico que acometem o paciente hospitalizado: 
Quadro 1 - Aspectos subjetivos no ambiente hospitalar.

\begin{tabular}{|l|l|}
\hline \multicolumn{1}{|c|}{ CATEGORIAS } & \multicolumn{1}{c|}{ CARACTERÍSTICAS } \\
\hline Ameaça básica a integridade narcísica & $\begin{array}{l}\text { São atingidas as fantasias onipotentes de imortalidade, de controle sobre o pró- } \\
\text { prio destino e de um corpo indestrutível. Podem emergir fantasias catastróficas, } \\
\text { com sensação de pânico, aniquilamento e impotência. }\end{array}$ \\
\hline Ansiedade de separação & Não só de pessoas significativas, mas de objeto, ambiente e estilo de vida. \\
\hline Medo de estranhos & $\begin{array}{l}\text { Ao entrar no hospital, o paciente coloca sua vida e seu corpo nas mãos de pes- } \\
\text { soas desconhecidas, cuja competência e intenção ele desconhece. }\end{array}$ \\
\hline Culpa e medo de retaliação & $\begin{array}{l}\text { Ideias de que a doença veio como um castigo por pecados e omissões, fantasias } \\
\text { de destruição de uma parte enferma do corpo, "traidora". }\end{array}$ \\
\hline Medo da perda do controle & $\begin{array}{l}\text { Funções adquiridas durante o desenvolvimento, como a fala, o controle dos } \\
\text { esfíncteres, a marcha, etc. }\end{array}$ \\
\hline Perda de amor e aprovação & $\begin{array}{l}\text { Sentimentos de autodesvalorização gerados pela dependência, sobrecarga finan- } \\
\text { ceira, etc. }\end{array}$ \\
\hline Medo de dano a partes do corpo & \begin{tabular}{l} 
Mutilações ou disfunções de membros e de órgãos alteram o esquema corporal. \\
\hline Medo da dor e da morte
\end{tabular} \\
\hline
\end{tabular}

Fonte: Borges Junior, Oliveira \& Peck Vasconcelos a partir de Strain (1978)

A doença pode ser vivenciada por algumas pessoas como um baque que se impõe ao sujeito, ocasionando o desabamento de sua integridade narcisista e do sentimento de onipotência, tal como é colocado na primeira categoria (Quadro 1) (Botega, 2017; Strain, 1978). Fala-se em um processo de despersonalização, uma vez que a hospitalização ultrapassa os limites e imposições do sujeito que deixa de significar a si mesmo para ser significado por meio de sua patologia (Aguiar, Cavalcante, Ramos \& Holanda, 2018; Angerami-Camon, Trucharte, Knijnik \& Sebastiani, 2003).

O paciente cardiopata vivencia a ameaça da perda, perde-se em termos de integridade, de autoconceito e de sua participação enquanto membro integrado ao ambiente que vive e a ansiedade leva o paciente a antecipar questões referentes a dor, a perda de controle sobre si mesmo e o medo de se ver dependente de alguém (Aguiar, Cavaltante, Ramos \& Holanda; Ragozini, Almeida, Pereira \& Barbosa, 2018).

É importante pensar que as unidades hospitalares, tal qual afirmam Aguiar, Cavalcante, Ramos e Holanda (2018), são ambientes que geram estresse aos pacientes, submete-os a um confinamento e, algumas vezes, a restrições de locomoção, ficando o paciente restrito ao leito, além do uso de aparelhos, os ruídos e a iluminação constantes, bem como a frequente realização de exames também contribuem para a construção de um ambiente que gera estresse ao sujeito, sem deixar de mencionar as alterações que sofre em sua rotina, o distanciamento das atividades laborais e sociais gerando um sentimento de despersonalização.

Psicanaliticamente, pode-se enxergar esse apanhado de fenômenos listados como ligados a partir de um ponto comum: a possibilidade da finitude do sujeito hospitalizado. Retomando Freud (1930/2017), ao dissertar sobre a civilização e o mal-estar que esta acarreta aos sujeitos que à compõe, elenca três fontes de sofrimentos ao humano.

Compõem estas o tempo, a natureza e o outro. Esses componentes representam a motivação subjacente a formação do processo civilizatório: a busca por proteção contra as investidas da natureza e a ideia de finitude (Freud, 1930/2018). Quanto aos aspectos subjetivos dispostos no quadro 1, pode-se sintetizá-los a partir da noção de mal-estar empregada por Freud (Freud, 1930/2018).

O período de adoecimento, a objetificação muitas vezes vividas no ambiente hospitalar (despersonalização, procedimentos invasivos e entre outros) lançam o sujeito a um estado de desamparo causado pela possibilidade da morte, aspecto do qual o psiquismo não possui representação, escrachando a característica do humano de um ser “insocorrível” (Ceccarelli, 2009).

Doravante isso, ao desenvolver a noção de desamparo, surgiu uma outra compreensão, a de gestão do desamparo (Birman, 2017), diz respeito aos destinos dados ao caráter faltoso que constitui o sujeito, mediante palavra. 
Com a oportunidade de falar a respeito do que atravessa o sujeito, este é deslocado de uma posição de passividade e é conduzido à potência de falar a partir do seu desejo.

Deste modo, observam-se dois pontos: o primeiro, é que o adoecimento é um fenômeno atravessado por questões de diversas ordens, sejam essas institucionais (hospitalares), culturais, ou de outra ordem, mas que podem vir a mobilizar o sujeito devido a possibilidade eminente da finitude. O segundo ponto diz respeito ao teor subjetivo que comporta os sintomas, que abre margem à riqueza de significados que podem ser atribuídos às vivências de adoecimento e hospitalização.

\section{Considerações finais}

O hospital é um ambiente que desperta sentimentos diversos no sujeito e, muitas vezes, não autoriza a elaboração desses. Nesse sentido, cabe ressaltar que, pelo caráter institucional, o hospital acaba por anular as subjetividades das pessoas que se encontram internadas, tornando todas "iguais", reduzindo suas existências às classificações nosológicas, números de leitos e entre outras violações.

No tocante a isso, ao refletir sobre a clínica cardiológica e seu caráter predominantemente paliativo em detrimento do curativo, questionou-se quanto às manifestações subjetivas presentes como resposta à experiência do adoecimento. Ora, como exposto, o padecimento é de caráter crônico, o que leva o sujeito a mudar totalmente o seu estilo de vida após o episódio de adoecimento.

Ademais, por uma das especificidades dessa clínica ser o procedimento cirúrgico, que é objeto de diversas fantasias do sujeito hospitalizado. Essas fantasias decorrem desde o medo da morte, falha da anestesia, reverberações na imagem corporal e entre outras. De maneira geral, esses componentes acarretam profunda mobilização psíquica não só ao paciente, mas às pessoas que o acompanham durante esse momento.

E é exatamente aí, na eclosão de mobilizações emocionais, que a escuta oferecida pelo psicanalista é de grande impacto. A partir da oportunidade de fala, o sujeito acometido por grande angústia tem a oportunidade de organização interna e simbolização de acontecimentos externos. Ou seja, a vivência de adoecimento pode ser em parte elaborada e resinificada a partir da atribuição de simbólico ao que, outrora, não tinha significação.

\section{Referências}

Aguiar, M. S. V.; Cavalcante, L. A.; Ramos, I. W. S.; Holanda, T. C. M. A (2018). Atuação do psicólogo hospitalar no atendimento a pacientes com doenças cardiovasculares: revisão de literatura. Diversidade de práticas em psicologia. Fortaleza, vol. 1, n. 1. Recuperado em 6 de abril de 2020 dehttp://www.crp11.org.br/upload/Publicacao-diversidade-praticas-em-psicologia-CRP11.pdf.

BATISTA, G; ROCHA, G. M (2013). A presença do analista no Hospital
Geral e o manejo da transferência em situação de urgência subjetiva. Rev. SBPH, Rio de Janeiro, v. 16, n. 2, p. 25-41, dez. recuperado em 6 de abril de 2020 de http://pepsic.bvsalud.org/scielo.php?script=sci_arttext\&pid $=\mathrm{S} 1516-08582013000200003$.

BENTO, M (2008). Corpo estranho - narcisismo e desamparo no contexto hospitalar. Rev. SBPH, Rio de Janeiro, v. 11, n. 1, p. 101-111, jun. recuperado em 6 de abril de 2020 de http://pepsic.bvsalud.org/scielo.php?script=sci_ar ttext\&pid=S1516-08582008000100008.

BERLINCK, M. T (2000). Psicopatologia fundamental. São Paulo: Escuta.

BIRMAN, J (2017). Mal-estar na atualidade: a psicanálise e as novas formas de subjetivação. Rio de Janeiro: Civilização brasileira.

BOTEGA, N, J (2017). O paciente diante da doença e da hospitalização. In: ______ (Org.). Prática psiquiátrica no hospital geral: interconsulta e emergência. $4^{\mathrm{a}}$ ed. São Paulo: Artmed. p. 24-37. Recuperado em 6 de abril de 2020 de https://books.google.com.br/books?id=BWAwDwAAQBAJ\& $\mathrm{pg}=\mathrm{PT} 254 \& \mathrm{dq}=$ botega $+\mathrm{n}+\mathrm{j} \& \mathrm{hl}=\mathrm{pt}-\mathrm{BR} \& \mathrm{sa}=\mathrm{X} \& \mathrm{ved}=0 \mathrm{ahUKEwjxw} 5$ -16NToAhWTGbkGHYrUAPwQ6AEIOjAC\#v $=$ onepage\&q $=$ botega $\% 20$ $\mathrm{n} \% 20 \mathrm{j} \& \mathrm{f}=$ false.

CECCARELLI, P. R. (2009). Laço social: uma ilusão frente ao desamparo. Reverso, v. 31, n. 58, p. 33-41. Recuperado em 6 de abril de 2020 de https:// dialnet.unirioja.es/servlet/articulo? codigo $=5470014$

FREUD, S (2018). Compêndio de Psicanálise. In: FREUD, S. Compêndio de Psicanálise e outros escritos inacabados. Belo Horizonte: Autêntica Editora. (original publicado em 1939)

FREUD, S (2010). O Mal-estar na civilização. In: FREUD, S. O Mal-estar na civilização, novas conferências introdutórias à psicanálise e outros textos. São Paulo: Companhia das Letras, 2010. (original publicado em 1930)

FREUD, S (2017). Sobre o início do tratamento. In: FREUD. S. Fundamentos da clínica psicanalítica. Belo Horizonte: Editora Autêntica, 2017. (original publicado em 1913)

GOMES, D. R. G (2008). O corpo psicanalítico no hospital. Dissertação de mestrado, Universidade Federal de Uberlândia, Uberlândia, MG, Brasil.

GOMES, D. R. G.; PRÓCHNO, C. C. S. C. (2015). O corpo-doente, o hospital e a psicanálise: desdobramentos contemporâneos? Revista Saúde e Sociedade, São Paulo, v. 24, n. 3, p. 780-791.

IMANISHI, H. A.; SILVA, L. L. (2016). Despersonalização nos hospitais: o estádio do espelho como operador teórico. Rev. SBPH, Rio de Janeiro, v. 19, n. 1, p. 41-56, jun. Recuperado em 6 de abril de 2020 de http://pepsic. bvsalud.org/scielo.php?script=sci_arttext\&pid=S1516-08582016000100004.

LAMOSA, B. W. (1990). Psicologia aplicada à cardiologia. In: Psicologia aplicada à cardiologia. São Paulo: Fundo Editorial BYK.

LIRA, D. A. (2015). Análise da argumentação de estudantes universitários em ensaios acadêmicos. Dissertação de mestrado, Universidade Federal de Pernambuco, PE, Brasil. 206 f.

MORETTTO, M. L. T. (2001). O que pode um analista no hospital? São Paulo: Casa do psicólogo.

OLIVEIRA, S. A.; OLIVEIRA, M. F. P (2010). Psicologia e cardiologia: um desafio que deu certo. In: Psicologia e cardiologia: Um desafio que deu certo. p. $1-5$

PECK VASCONCELOS, A. C.; LEVY, E. S. (2019). Uma perspectiva psicanalítica sobre a transitoriedade: análise da personagem Vivian do filme "Uma lição de vida". Estudos de Psicanálise. Belo Horizonte, n. 51, p. 17-24, jun. Recuperado em 6 de abril de 2020 de http://pepsic.bvsalud. org $/$ scielo.php? script $=$ sci_abstract\&pid $=$ S0100-34372019000100002\&lng $=\mathrm{pt \& nrm}=$ iso\&tlng $=\mathrm{pt}$.

RAGOZINI, C. A; ALMEIDA, C. P.; PEREIRA, J. A.; BARBOSA, L. N. F. (2010) A atuação da psicologia clínica hospitalar em cardiologia. In: Ismael, S. M. C. (Org.) A prática psicológica e sua interface com as doenças (pp. 114-129).

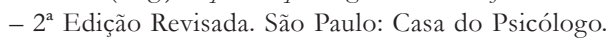

SIMONETTI, A (2004). Manual de Psicologia Hospitalar: o mapa da doença. São Paulo: Casa do Psicólogo.

SOUZA, R. O. P. (2017). História da cardiologia no Brasil: a construção de uma especialidade médica (1937-1958). Dissertação de mestrado, Fundação Oswaldo Cruz, Rio de Janeiro, RJ, Brasil. 169 f.

Submetido em: 1-5-2020

Aceito em: 10-01-2021 